\title{
Pore Structure Characteristics of Baking-Free Slag-Sludge Bricks and Its Correlations to Mechanical Properties
}

\author{
Lei Guo ${ }^{1,2,3,4}$, Pingping Chen ${ }^{1}$, Lixia Guo ${ }^{1,2,3, *}$, Zhilong Xue ${ }^{4}, Z_{i}$ Guan $^{1}$ and Mingru Li $^{1}$ \\ ${ }^{1}$ School of Water Conservancy, North China University of Water Resources and Electric Power, Zhengzhou, 450046, China \\ ${ }^{2}$ Henan Water Valley Research Institute, Zhengzhou, 450046, China \\ ${ }^{3}$ Henan Key Laboratory of Water Environment Simulation and Treatment, Zhengzhou, 450002, China \\ ${ }^{4}$ Henan Water Conservancy Investment Yuyuan Water Ecology Co. Ltd., Pingyu, 463400, China \\ *Corresponding Author: Lixia Guo. Email: guolx@126.com
}

Received: 25 November 2020 Accepted: 30 December 2020

\begin{abstract}
In order to explore the relationship between the macroscopic properties and pore structure characteristics of baking-free slag-sludge bricks, the compressive strength and water absorption rate using aluminum industrial slag and sludge of different substitution rates were tested. Optical instruments and image analysis software were used to measure the parameters of the pore structure. Specifically, a fractal model was built based on the fractal theory, in which the fractal dimension was used as the characteristic index of the pore structure to analyze the correlation and interaction mechanism between the fractal dimension and the macroscopic mechanical properties. Based on this study, conclusions were drawn as follows: (1) The plane pore structure of baking-free bricks shows good fractal characteristics. With the increase of the aluminum industrial slag content, the fractal dimension becomes smaller and the pore structure develops well; with the increase of the sludge content, the fractal dimension becomes larger and the pore structure becomes worse; (2) As the fractal dimension of the plane pore structure increases, the compressive strength of baking-free bricks falls, and the porosity and water absorption rise; (3) The optimum content of baking-free slag-sludge bricks is aluminum industrial slag $30 \%$ and sludge $10 \%$. After 7 days of curing, baking-free bricks boast higher performance, and fully meet the performance requirements of solid concrete bricks (MU40), which can reduce time costs, and enhance enterprise revenue.
\end{abstract}

\section{KEYWORDS}

Aluminum industrial slag; sludge; baking-free brick; mechanical property; fractal dimension

\section{Introduction}

Baking-free concrete bricks are made of cement, aggregates, required admixtures and additives by mixing with water, molding and curing, and feature regular size and high strength. With the improvement of solid waste recycling technology, using massive low-cost urban solid waste as a substitute for conventional raw materials to mix with concrete materials has become a research trend and offers a direction for material development [1-3]. In China, the annual discharge of slag is up to tens of millions of tons, which not only occupies land resources, but also threatens the safety of the ecological environment [4]. In recent years, many researchers have used slag as a raw silicon aluminum material to 
prepare a "geopolymer" green inorganic cementing material $[5,6]$. Due to its advantages of high strength, excellent resistance to penetration, good durability, and good sealing ability for toxic metals, the "geopolymer" green inorganic cementing material has replaced conventional portland cement used in the industrial and civil construction and nuclear industry [7-10].

The sludge disposal policy based on the differences in sludge sources, composition and physical properties gives rise to a plurality of utilization methods such as composts, soil improvers, product recycling, cementing materials and building material production [11,12]. Xu et al. [13] adopted red mud, fly ash and other solid wastes produced in the process of smelting alumina to prepare baking-free bricks and studied their mechanical properties and durability. A new process for preparing baking-free bricks using non-sintered wrap-shell lightweight aggregates made from dredged sludge, and studied their density, water absorption rate, compressive strength and frost resistance [14]. A research used drinking water sludge (DWS) and rice husk ash (RHA) to make alternative bricks and believed that the firing temperature can modify and enhance the studied mechanical characteristics [15]. Carlos et al. [16] developed concretes consisting of a cement matrix, silica, sand, marble and sludges, a way of utilizing sludge is thus provided together with a way to improve the compressive strain at yield point of concrete. Zhou et al. [17] put forward that the preparation of porous insulation bricks based on municipal sewage sludge to realize environment protection and waste reclamation. From these related studies, it can be found that the application of sludge in the construction industry for resource utilization has become a research trend.

However, the preparation process of baking-free bricks is different from that of concrete, and it is easy to form a porous structure; the pores, number of voids, and distribution characteristics affect the mechanical properties and damage evolution of the materials [18-20]. The porosity, as a characteristic parameter of the pore structure of materials, is hard to accurately quantify the complex pore structure of materials. The emerged CT, MIP, NMR and other scanning imaging techniques and fractal methods provide opportunities for a comprehensive study of the pore structure of cement-based materials [21,22]. Many studies have proposed using the fractal theory to characterize the complex pore structures, and confirmed the correlation between the fractal dimension and macroscopic properties of materials [23,24]. Therefore, studying the pore structure characteristics of baking-free slag-sludge bricks is of great significance for enhancing the performance of baking-free slag-sludge bricks.

Based on the material effects of slag and the active components in the sludge, this paper started from the perspective of solid waste recycling, and intended to prepare baking-free slag-sludge bricks by mixing admixtures and press-vibration molding. The laboratory test and fractal theory were used to study the pore structure characteristics of baking-free slag-sludge bricks and their relationship with the bricks' performance and analyze the effect of the admixture and sludge content on the performance, and suggestions for optimization of applying sludge to baking-free bricks were proposed. This study provided a theoretical basis for the extension of such resource utilization technology as using solid waste materials as an admixture in baking-free bricks.

\section{Raw Materials and Test Methods}

\subsection{Raw Materials}

Cement was $\mathrm{P} \bullet \mathrm{O} 42.5$ ordinary Portland cement from Tianrui, whose key performance indicators are as shown in Tab. 1.

Aluminum Industrial Slag is produced Henan Yulian Energy Group Co., Ltd., referred to as slag in the text, white, oxide composition of slag shown in Tab. 2. 
Table 1: Physical and mechanical properties of cement P.II.42.5

\begin{tabular}{|c|c|c|c|c|c|c|c|}
\hline \multirow[t]{2}{*}{$\begin{array}{l}\text { Specific surface } \\
\text { area } /\left(\mathrm{m}^{2} \cdot \mathrm{kg}^{-1}\right)\end{array}$} & \multirow[t]{2}{*}{$\begin{array}{l}\text { Density } \\
/\left(\mathrm{kg} \cdot \mathrm{m}^{-3}\right)\end{array}$} & \multicolumn{2}{|c|}{$\begin{array}{l}\text { Setting } \\
\text { time/min }\end{array}$} & \multicolumn{2}{|c|}{ Compressive strength/MPa } & \multicolumn{2}{|c|}{ Flexural strength/MPa } \\
\hline & & Initial & Final & Three days & Twenty-eight days & Three days & Twenty-eight days \\
\hline 348.7 & 3035 & 176 & 244 & 25.9 & 49.6 & 5.9 & 8.6 \\
\hline
\end{tabular}

Table 2: Oxide composition of slag and cement powder

\begin{tabular}{llllllllll}
\hline Chemical constituents $/ \%$ & $\mathrm{CaO}$ & $\mathrm{Fe}_{2} \mathrm{O}_{3}$ & $\mathrm{SO}_{3}$ & $\mathrm{Al}_{2} \mathrm{O}_{3}$ & $\mathrm{MgO}$ & $\mathrm{SiO}_{2}$ & $\mathrm{~K}_{2} \mathrm{O}$ & $\mathrm{Na}_{2} \mathrm{O}$ & LOI \\
\hline Cement & 51.27 & 3.65 & 2.46 & 9.25 & 4.98 & 24.13 & 0.79 & 1.95 & 3.55 \\
Slag & 0.57 & 1.94 & - & 24 & 1.22 & 47.6 & 7.43 & - & 2.43 \\
\hline
\end{tabular}

Sludge was taken from a lake in Zhengzhou, and after drying, impurity removal and screening, its bulk density was $1,218.0 \mathrm{~kg} / \mathrm{m}^{3}$, no heavy metals and odor. Coarse aggregates was selected gravel with the diameter of $5 \mathrm{~mm}-10 \mathrm{~mm}$ and bulk density of $1,541.3 \mathrm{~kg} / \mathrm{m}^{3}$. Sand was bought from Tanghe County Xinmiao Sand Co., Ltd., with a bulk density of $1,625.0 \mathrm{~kg} / \mathrm{m}^{3}$, a fineness modulus of 2.95 , and a clay content of $1.5 \%$. Passing rate of aggregates curve is shown in Fig. 1.

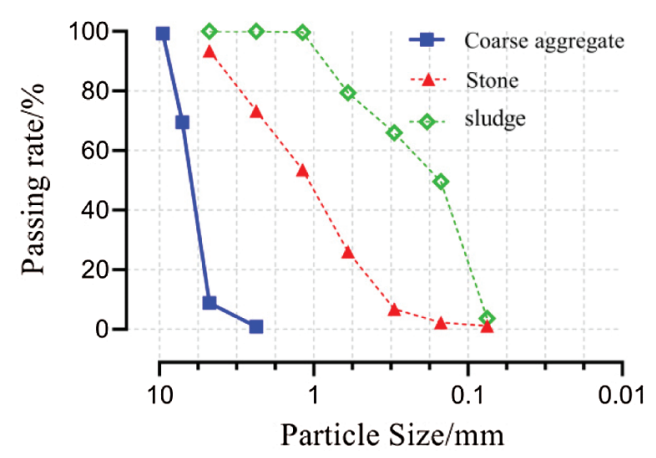

Figure 1: Passing rate of aggregates

Water-reducing agent mixed by $1 \%$ was naphthalene series water reducer.

Activator mixed by $1 \%$ was $\mathrm{NaCl}+\mathrm{Na}_{2} \mathrm{SO}_{4}$ solid powder composite activator. Among then, the waterreducing agent and the activator were both admixtures, which is the mass fraction of the cementing material.

\subsection{Specimen Molding and Curing}

The baking-free slag-sludge bricks adopted the self-made mold as shown in Fig. 2. The prepared brick samples with specifications of $240 \mathrm{~mm} \times 115 \mathrm{~mm} \times 53 \mathrm{~mm}$ can be seen in Fig. 3, The standard design strength was MU40 [25]. First, 10\% slag and 10\% sludge were taken as the baseline group. In the first stage, slag was used to replace cement, with the replacement rate increasing from $10 \%$ to $40 \%$. Through the performance test, the optimal replacement rate was 30\%. In the second stage, $30 \%$ slag and $10 \%$ sludge were taken as the baseline group, and the sludge replacement rate increased to $50 \%$. Details of the mix ratio are shown in Tab. 3. 


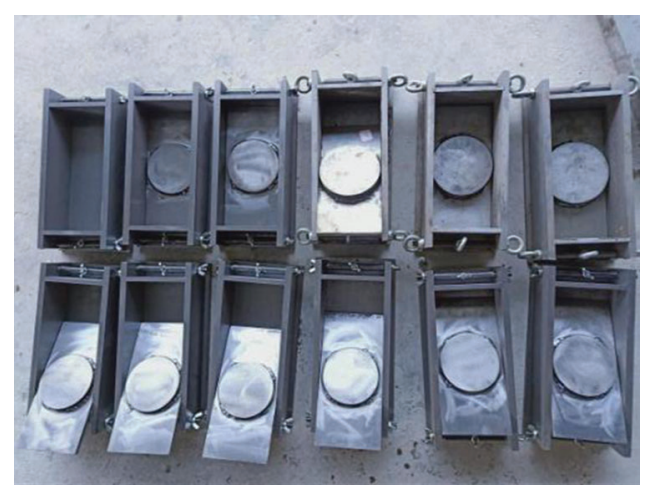

Figure 2: Self-made mold

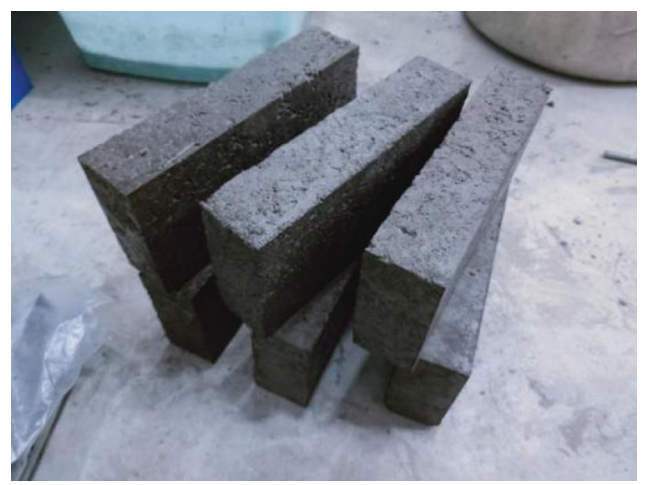

Figure 3: Baking-free brick

Table 3: Baking-free brick mix design

\begin{tabular}{lllllllll}
\hline \multicolumn{2}{c}{ Sample Cement } & $\begin{array}{l}\text { Stone } \\
\mathrm{kg} / \mathrm{m}^{3}\end{array}$ & $\begin{array}{l}\text { Slag } / \mathrm{m}^{3} \\
\mathrm{~kg} / \mathrm{m}^{3}\end{array}$ & $\begin{array}{l}\text { Sludge } \\
\mathrm{kg} / \mathrm{m}^{3}\end{array}$ & $\begin{array}{l}\text { Sand } \\
\mathrm{kg} / \mathrm{m}^{3}\end{array}$ & $\begin{array}{l}\text { Water- } \\
\text { binder ratio }\end{array}$ & Activators/\% & $\begin{array}{l}\text { Water-reducing } \\
\text { agent } / \%\end{array}$ \\
\hline $\mathrm{SS} 1$ & 288 & 900 & 32 & 95 & 885 & 0.36 & 1 & 1 \\
$\mathrm{SS} 2$ & 256 & 900 & 64 & 95 & 885 & & $\mathrm{NaCl}_{2}:$ & \\
$\mathrm{SS} 3$ & 224 & 900 & 96 & 95 & 885 & & & \\
$\mathrm{SS} 4$ & 192 & 900 & 128 & 95 & 885 & & & \\
$\mathrm{SS} 5$ & 224 & 900 & 96 & 190 & 760 & & & \\
$\mathrm{SS} 6$ & 224 & 900 & 96 & 285 & 665 & & & \\
$\mathrm{SS} 7$ & 224 & 900 & 96 & 380 & 570 & & & \\
$\mathrm{SS} 8$ & 224 & 900 & 96 & 475 & 475 & & & \\
\hline
\end{tabular}

Note: Both the water reducing agent and the activator are externally blended, which is the mass fraction of the cementing material

First, weigh the aggregates, cementing materials and sludge particles and then the mixture was stirredin a mixer for $30 \mathrm{~s}$. Then the water reducing agent and the activator were added about $80 \%$ of the water in the mixer and stirring was continued for $60 \mathrm{~s}$. A remaining water was then poured in to mixer, stirred for $240 \mathrm{~s}$. Finally, the resultant mixture was poured into molds and formed through vibration and vertical compression. The pressure source is self-made counterweight with a weight of $20 \mathrm{~kg}$, as shown in Fig. 4. 
After the mold was removed, the molding test block was transferred to a standard curing room $\left(20 \pm 2{ }^{\circ} \mathrm{C}\right.$, 95\%) for 7 days before the performance test was carried out.

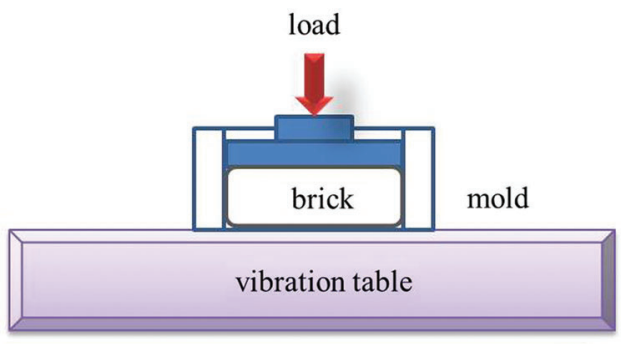

Figure 4: Baking-free brick molding process

\subsection{Experimental Method}

\subsubsection{Compressive Strength Test}

The test specimen was prepared according to the "Test Methods for the Concrete Block and Brick" [25], referring to Fig. 5. The test used a WAW-1000 electro-hydraulic servo universal testing machine. During the test, the specimen was placed flat in the center of the compression plate, a load was applied perpendicular to the pressure surface at a speed of $5 \mathrm{kN} / \mathrm{s}$ until the specimen broke, and at that time, the peak failure load $\mathrm{P}$ was recorded to calculate the compressive strength.

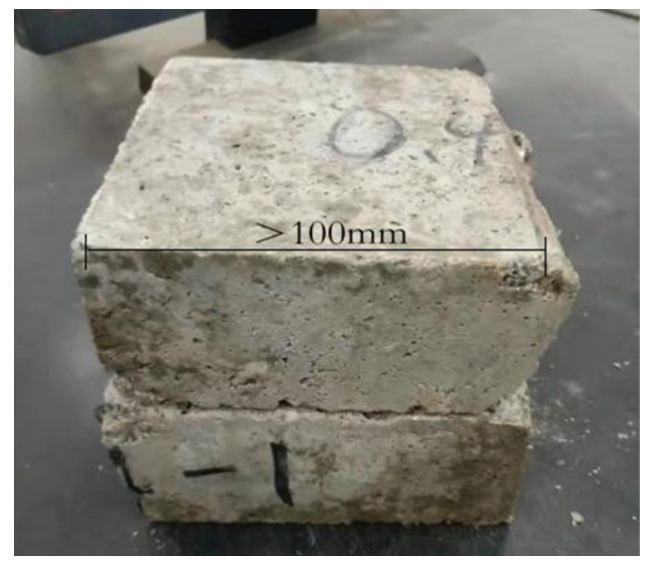

Figure 5: Compressive strength text-block

\subsubsection{Water Absorption Test}

The $24 \mathrm{~h}$ water absorption rate was used to characterize the water absorption capacity of baking-free bricks. Test blocks were absolutely dried at $100^{\circ} \mathrm{C}$ in the ZTE 202 electrothermal constant-temperature drying box, then taken out and measured after cooling down to the room temperature, with the mass denoted by $m_{0}$. The test blocks were placed in water at average $21^{\circ} \mathrm{C}$ for $24 \mathrm{~h}$, and then taken out for measurement after the water on the surface was wiped with a wet towel. The weight of water leaking from the pores on the surface of the specimen during the weighing was also included in the water absorption mass, and the mass obtained was $\mathrm{m}_{24}$. The water absorption rate $\mathrm{W}_{24}$ was calculated according to the following Eq. (1) [25]. 
$W_{24}=\frac{m_{24}-m_{0}}{m_{0}} \times 100 \%$

where, $W_{24}$ is water absorption rate of the specimen at $24 \mathrm{~h} ; m_{24}$ is mass of the specimen after saturation (accurate to $0.01 \mathrm{~g}$ ); $m_{0}$ is absolute dry mass (accurate to $0.01 \mathrm{~g}$ ).

\subsubsection{Micro Structure Analysis}

Baking-free bricks was sampled with their original shape retained. A small amount of residual blocks were tweezered and fixed on the conductive adhesive of the sample pedestal with the fracture surface facing up, and then coated before analysis and detection. The instrument used was QUANTA650 environmental scanning electron microscope (ESEM) from EDAX Company. The measurement was carried out under the following conditions: working voltage $25 \mathrm{kV}$, working distance $10 \mathrm{~mm}$, and scanning time $30 \mathrm{~s}$.

\subsubsection{Pore Structure Test}

The pore structure characteristics of baking-free bricks were obtained by using the optical method in combination with the image recognition software and the optical instrument. The extractable plane pores were larger than $200 \mu \mathrm{m}$. The industrial-grade camera was used to capture the image of the upper and lower parts of the cut face. Clipping and brightness of the collected images were applied using the Photoshop (PS) technology. Pores and Cracks Analysis System (PCAS) software was used with reference to the technique adopted by Liu et al. [26]. By setting an appropriate threshold value, the image of the cut face was grayed to highlight the plane pore distribution in the image to establish its binary feature, where the black parts represent the pores on the cut facewhile the brown parts are the aggregate and the cementing slurry. The binary image of the pore distribution was converted into two indicators of plane porosity and fractal dimension for quantization [27]. The test process is as shown in Fig. 6.
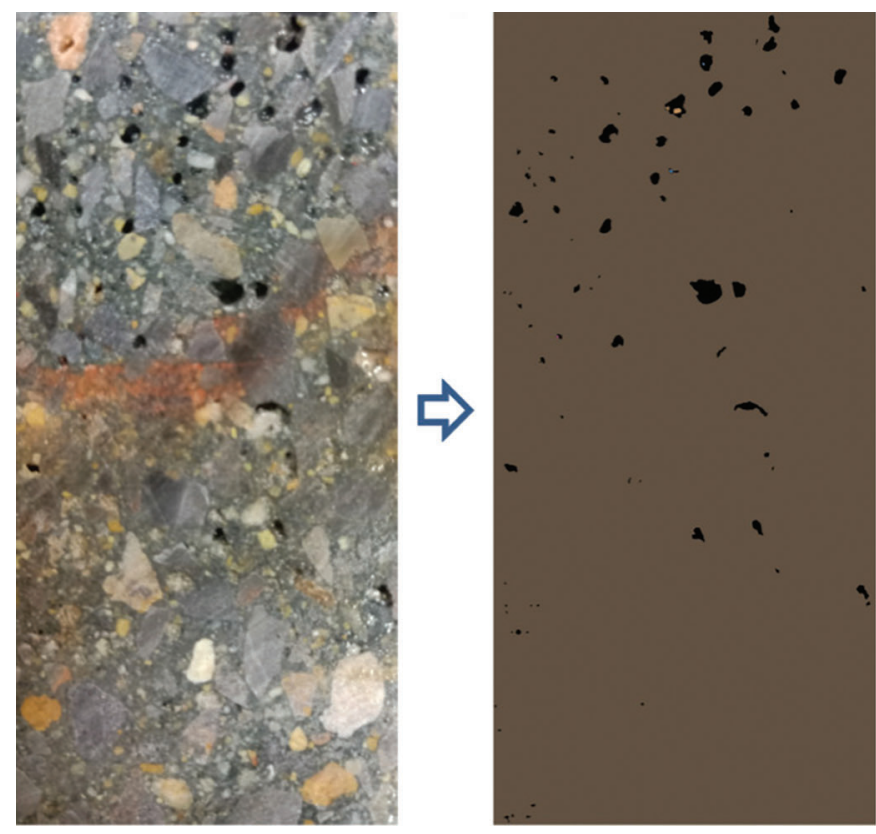

\begin{tabular}{|l|l|}
\hline Parameter & Value \\
\hline Image area/pixel & 9468096 \\
\hline Total region area & 109817 \\
\hline Region number & 83 \\
\hline Region percentage (Porosity) & $1.16 \%$ \\
\hline Haximum region area & 16347 \\
\hline Average region area & 1323.1 \\
\hline Average perimeter & 147.23 \\
\hline Average form factor & 0.4352 \\
\hline Marimum length & 192.26 \\
\hline Average length & 44.65 \\
\hline Marimum width & 137.8 \\
\hline Average width & 28.81 \\
\hline Probability Entropy & 0.943 \\
\hline Fractal dimension & 0.9033 \\
\hline Area probability distribution index & 1.227 \\
\hline Pore porosity distribution fractal dimension & 0.8158 \\
\hline Sorting Coefficient & 1.37078280497971 \\
\hline Uniformity Coefficient & 1.45902034424018 \\
\hline Curvature Coefficient & 1.0245568230328 \\
\hline
\end{tabular}

Figure 6: Pore structure test process 


\section{Image-Based Fractal Calculation}

Fractal analysis was firstly introduced by Mandelbrot to natural science in the 1970s to characterize complex figures and processes [28]. Fractal theory can provide a quantitative description of complex or extremely irregular shapes or behaviors with self-similar or statistically self-similar characteristics in nature. Fractal dimension divides the geometric hierarchy from various angles and measures the system's ability to fill space and the disorder of the system. For geometric shapes with certain dimensions, $D$ calculation Eq. (2) is as follows:

$D=\frac{\log N_{k}}{\log 1 / \mathrm{k}}$

where: $k$ represents the reference scale; $N_{k}$ represents the total number of line segments measured using the reference scale $k$.

The fractal model of baking-free bricks was built using the optical method. Considering the data characteristics and the relatively simple numerical calculation of box counting dimension, the box counting dimension was introduced to characterize the pore distribution rule and its impact on the macroscopic performance of baking-free bricks. The fractal set was selected and then was covered using the box of size, r. The number of occupied boxes was marked, $N(r)$ With the change of $r, N(r)$ will inevitably change. When $r \rightarrow 0$, the fractal dimension, $D$ is obtained from Eq. (3) [23]:

$D=-\lim _{r \rightarrow 0} \frac{\log N_{r}}{\log 1 / \mathrm{r}}$

The main process of the box counting method based on binary image is shown in Fig. 7. The boxcounting was then calculated using the Matlab's Fraclab toolbox.

\section{Results and Analyses}

Tab. 4 shows the experiment results, and Fig. 8 shows the fractal dimension calculation results. It can be found that for the plane pore structure of the same series of baking-free bricks, the fractal dimension can better characterize the development law of the pore structure. The correlation index $\mathrm{R}^{2}$ of box-counting fitting curve was greater than 0.9 , indicating that the plane pore structure of baking-free bricks has good fractal characteristics.

\subsection{Relationship between Fractal Dimension and Plane Porosity}

As seen from Fig. 9a, with the increase of the slag content, the porosity decreases. The plane porosity and fractal dimension both show a downward trend, and their correlation is positive. The increase of slag makes the plane pore structure more uniform, the pore size smaller and the regularity much better, which indicates that the micro-aggregate effect of slag can effectively improve the pore structure of baking-free bricks, decreasing the porosity. It can be seen from Fig. 9b that when the sludge content remains unchanged at $30 \%$, with the increase of the sludge content, the plane porosity undergoes a slow to abrupt increase, and the fractal dimension decreases first and then increases. When the sludge content exceeds $20 \%$, the pore structure of baking-free bricks begins to worsen and evolves into an irregular shape.

That's because that: (1) As the sludge content increases, particles in the aggregates also increase and wrap on the surface of coarse aggregates and fine sand, resulting in the decrease of the fluidity of bakingfree brick mixtures and the increase of the irregularity of the pores formed; (2) The flocculation of the sludge particles makes the pore structure changed from elliptical closed pores to small and interconnected irregular pores, and the more the sludge is added, the more irregular the pore structure is, so the fractal dimension increases and the pore structure deteriorates. In summary, there is a good positive correlation between fractal dimension and plane porosity. The larger the fractal dimension is, the more the large 
pores are or the more complex the pore structure will be. Therefore, under certain conditions, the relative size of the porosity and the change trend of the pore structure can be inferred from the fractal dimension of the plane pore structure [29].

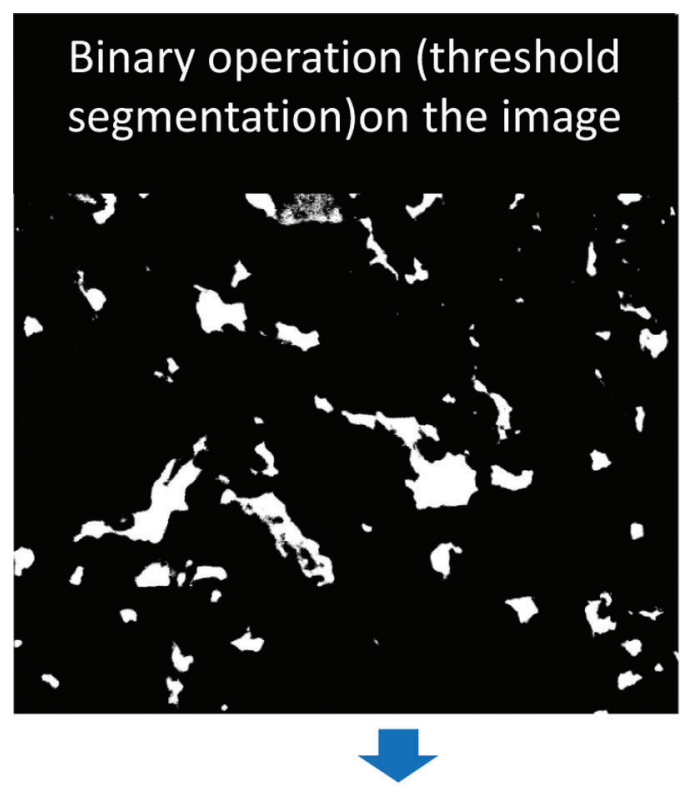

Select the linear fit and the range of fit

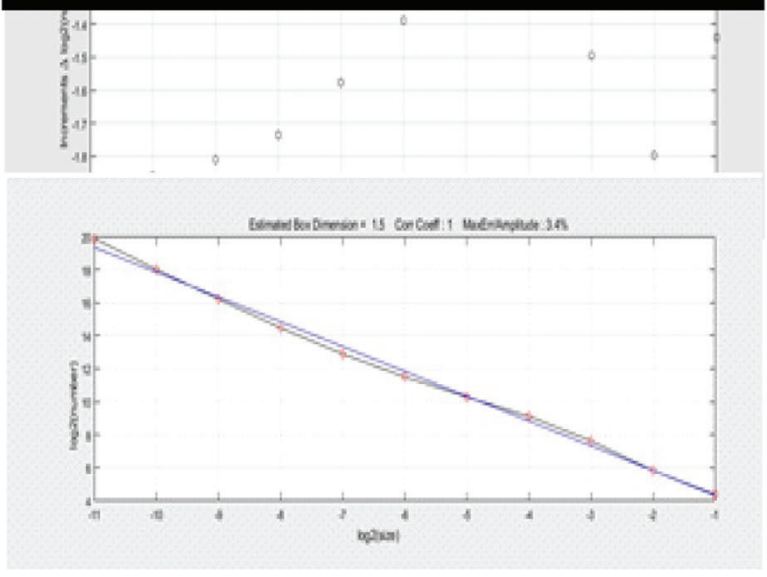

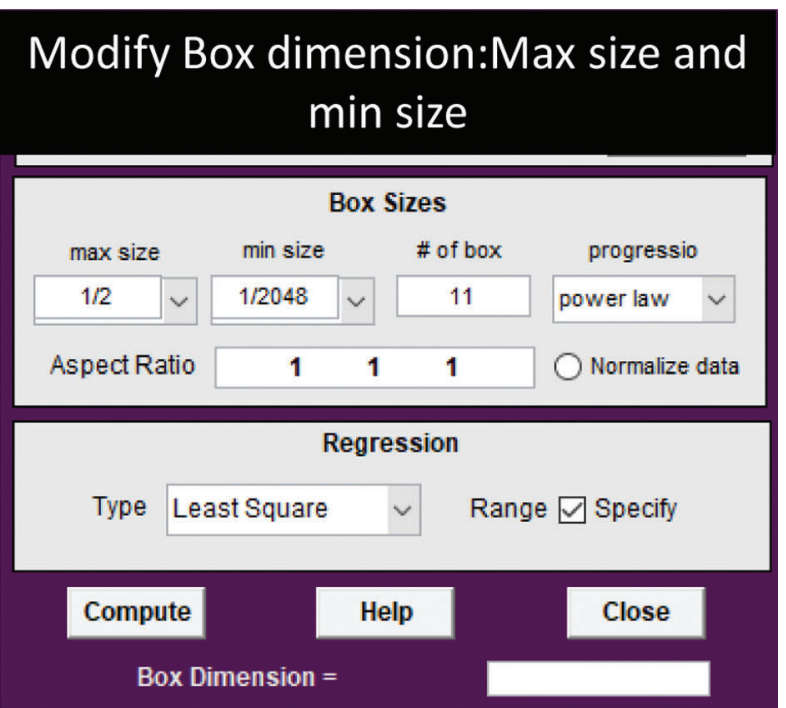
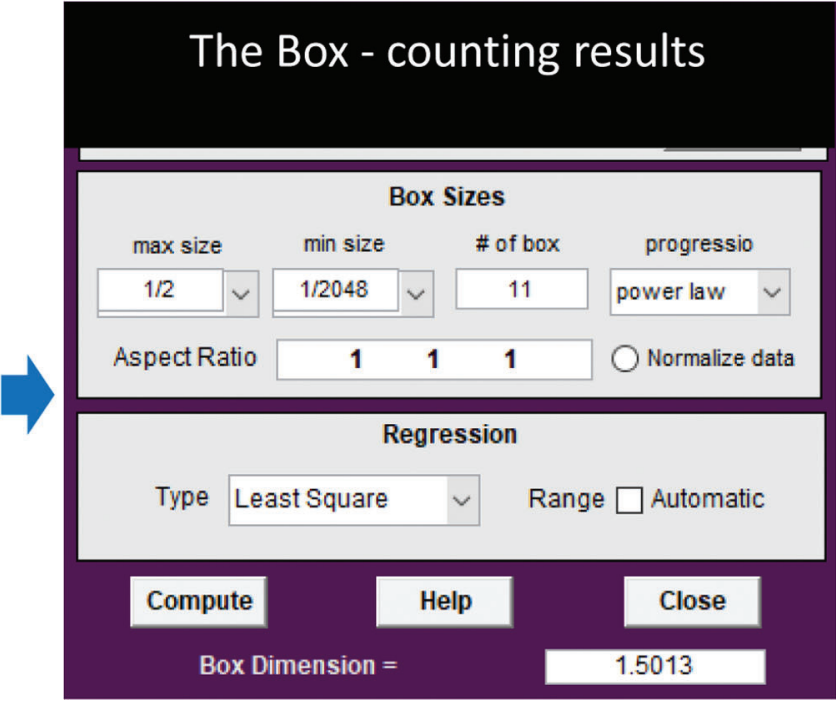

Figure 7: Box-counting calculation process

Table 4: Experiment results

\begin{tabular}{llllllllll}
\hline Sample & $\begin{array}{l}\text { Fractal } \\
\text { dimension }\left(\mathrm{R}^{2}\right)\end{array}$ & $\begin{array}{l}\text { Compressive } \\
\text { strength/MPa }\end{array}$ & $\begin{array}{l}\text { Plane } \\
\text { porosity/\% }\end{array}$ & $\begin{array}{l}\text { Water } \\
\text { absorption/\% }\end{array}$ & Sample & $\begin{array}{l}\text { Fractal } \\
\text { dimension }\left(\mathrm{R}^{2}\right)\end{array}$ & $\begin{array}{l}\text { Compressive } \\
\text { strength/MPa }\end{array}$ & $\begin{array}{l}\text { Plane } \\
\text { porosity/\% } \%\end{array}$ & $\begin{array}{l}\text { Water } \\
\text { absorption/\% }\end{array}$ \\
\hline SS1 & $1.46(0.996)$ & 24.04 & 8.30 & 2.70 & SS5 & $1.09(0.984)$ & 27.50 & 2.55 & 2.78 \\
SS2 & $1.37(0.945)$ & 28.22 & 5.47 & 2.48 & SS6 & $1.12(0.939)$ & 17.31 & 4.21 & 6.02 \\
SS3 & $1.33(0.925)$ & 43.86 & 2.40 & 2.13 & SS7 & $1.23(0.997)$ & 16.07 & 4.76 & 6.64 \\
SS4 & $1.13(0.923)$ & 32.20 & 2.29 & 2.03 & SS8 & $1.50(0.993)$ & 14.19 & 5.31 & 8.21 \\
\hline
\end{tabular}



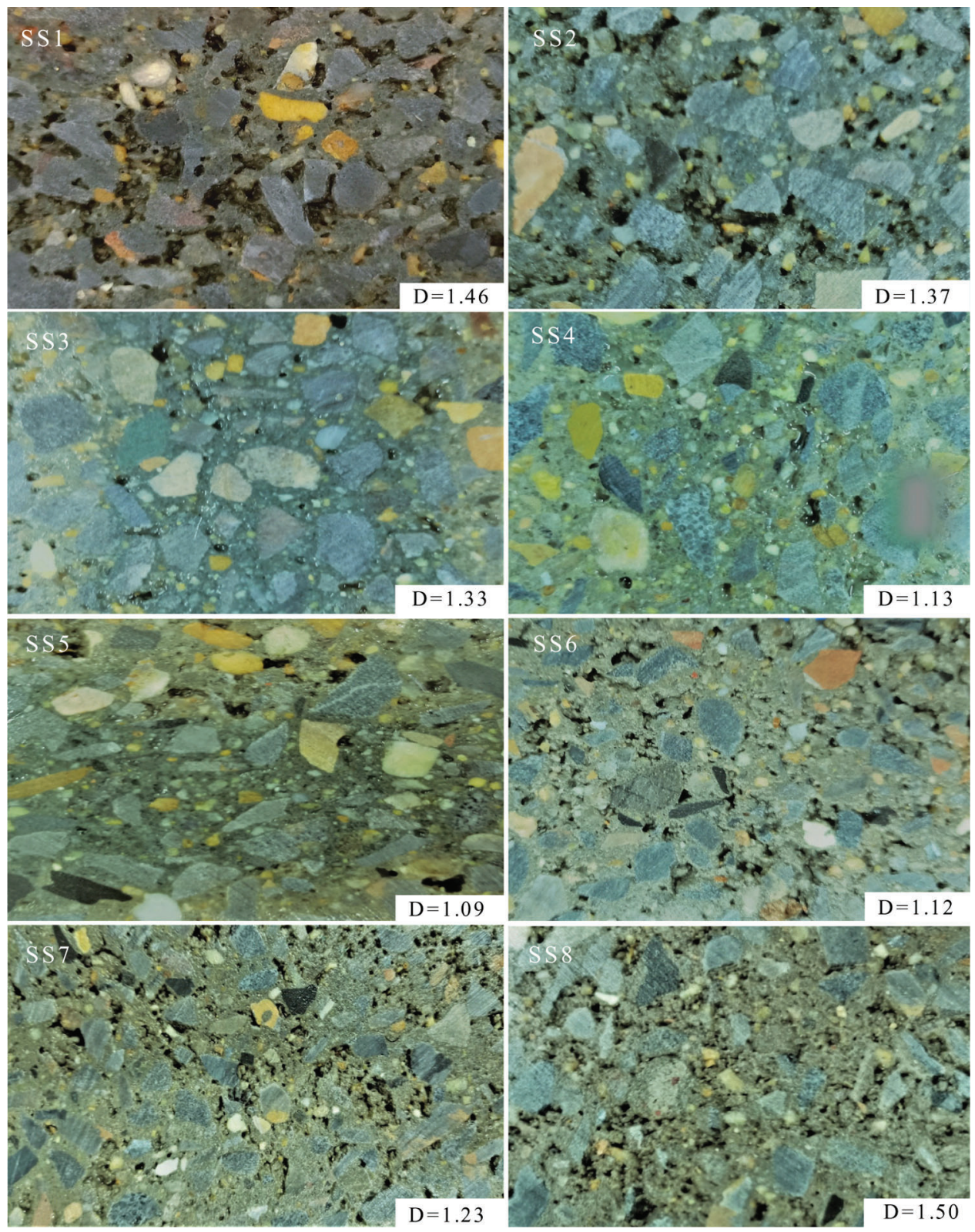

Figure 8: Results of fractal dimension calculation

\subsection{Relationship between Fractal Dimension and Water Absorption}

The relationship between fractal dimension and water absorption at different slag content is shown in Fig. 10a. With the increase of the slag content, the fractal dimension and water absorption rate both decrease, and maintain a good positive correlation, because the porosity of baking-free bricks gradually decreases and the pores become much smaller, resulting in a decrease in water absorption capacity. The relationship between fractal dimension and water absorption at different sludge content is shown in Fig. $10 \mathrm{~b}$. When the sludge content is more than $20 \%$, the water absorption rate and fractal dimension of baking-free bricks continue to increase, showing a basically positive correlation. 


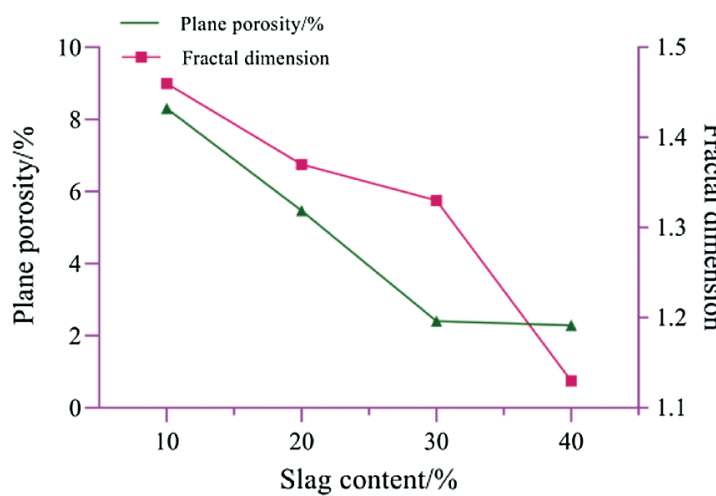

(a)

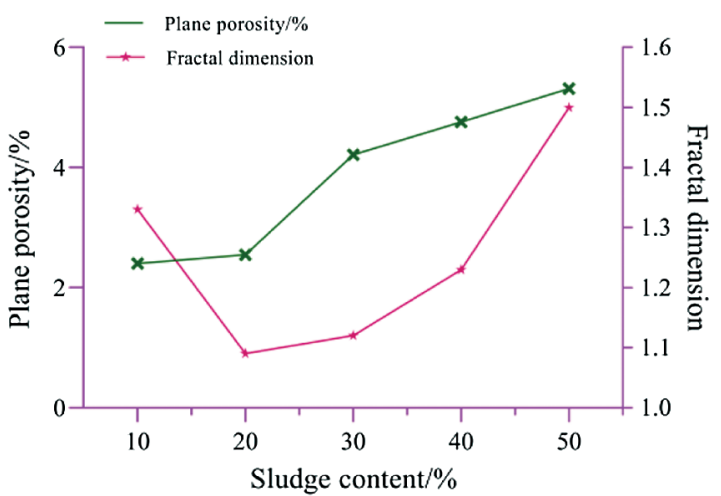

(b)

Figure 9: Relationship between fractal dimension and plane porosity for (a) Different slag contents and (b) Sludge contents

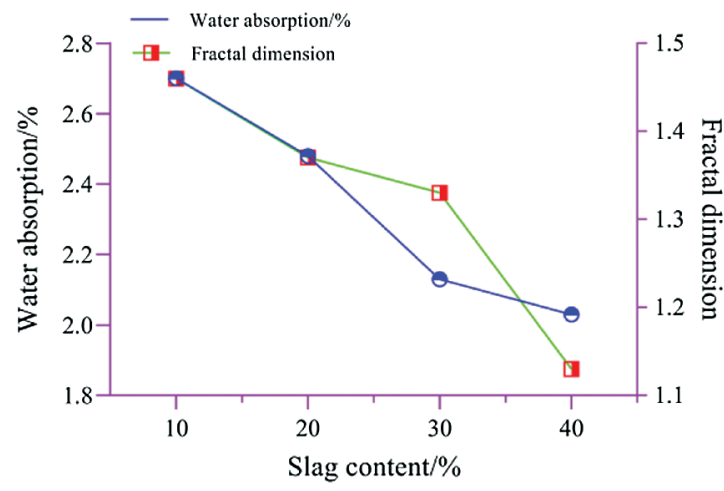

(a)

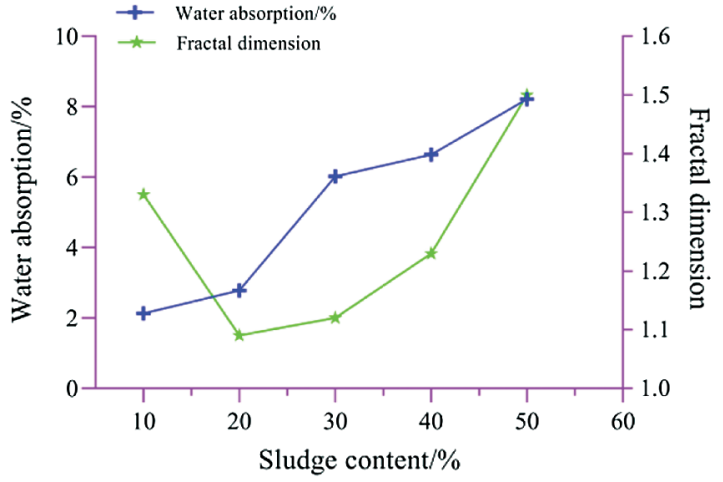

(b)

Figure 10: Relationship between fractal dimension and water absorption at (a) Different slag content and (b) Sludge content

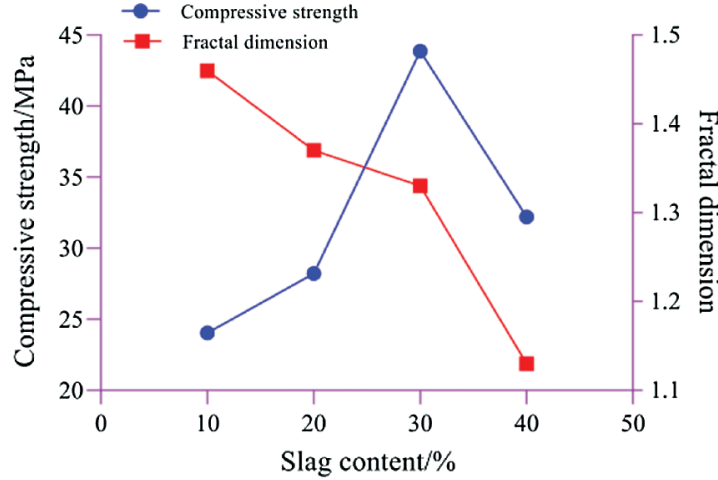

(a)

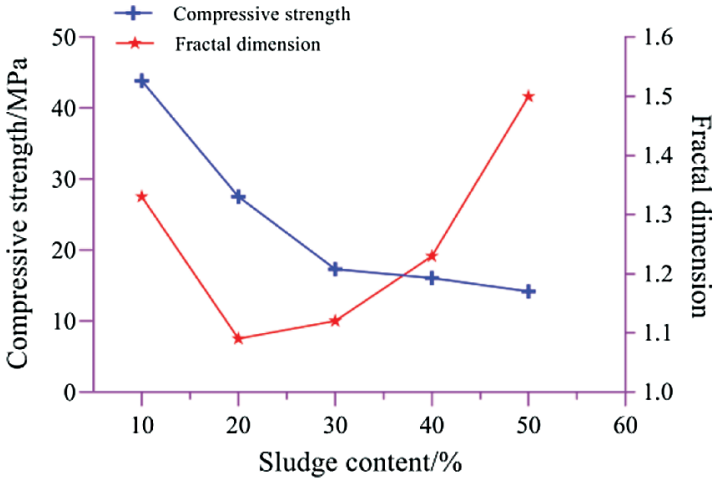

(b)

Figure 11: Relationship between fractal dimension and compressive strength at (a) Different slag content and (b) Sludge content 
This is because a large amount of sludge mixed reduces the fluidity of the mixture of baking-free bricks, changes the stacking method among the aggregates, and leads to poor wrapping of cementing materials on the aggregates [30]. In such case, large pores are easily formed at the interface between the aggregates and the mortar, increasing the fractal dimension and the water absorption rate, as exhibited in Fig. 12 [31]. When the sludge content is within $10 \%-20 \%$, the water absorption rate and fractal dimension has no marked relationship. This is because in this paper, the fractal dimension was used to reflect the characteristics of the pore structure with the pore diameter greater than $200 \mu \mathrm{m}$, while the water absorption rate was used to reflect the volume of all pores.

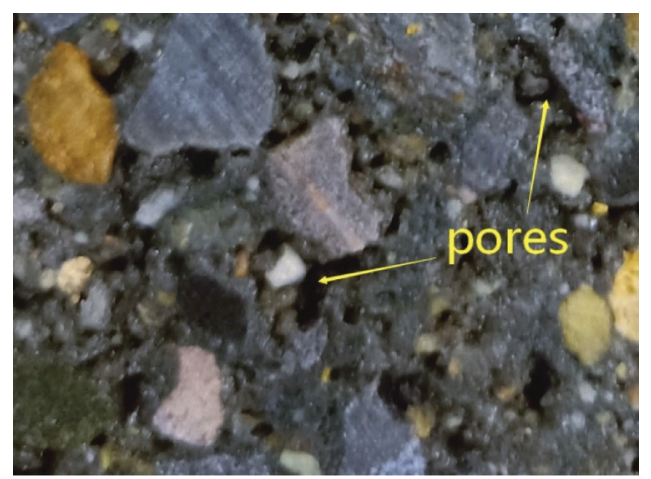

Figure 12: Baking-free brick slice images

\subsection{Relationship between Fractal Dimension and Mechanical Properties}

Fractal dimension as a comprehensive description of the pore structure of a material can directly reflect the pore structure quality, indicating that it has a correlation with mechanical properties of the material $[23,32]$. It can be seen from Fig. 11a that with the decease of the fractal dimension, the overall compressive strength increases, indicating that the two factors are negatively correlated. When the slag content is at $30 \%$, the compressive strength of baking-free bricks reaches the peak value (43.86 MPa) and fully meet the performance requirements of solid concrete bricks (MU40). Upon analysis, we found two reasons: (1) The pozzolanic effect of slag [33-35]. The slag improves the micro-pore structure of bakingfree bricks, reduces the porosity of the cement paste and the fractal dimension, strengthens the adhesive force at the aggregate interface, and thus increases the overall strength, as shown in Fig. 13; (2) The action of composite activators [36]. The activators $\mathrm{Na}_{2} \mathrm{SO}_{4}$ and $\mathrm{NaCl}$ diffuse to the hydration layer on the surface of slag particles, advancing the pozzolanic reaction of slag; besides, they react with the active $\mathrm{Al}_{2} \mathrm{O}_{3}$ to generate hydrated calcium sulcitrate (i.e., ettringite) and hydrated calcium chloroaluminate, causing the increase in solid phase ratio and the decrease in porosity, so the fractal dimension decreases and the compressive strength increases. The composite activator, the material effect of slag and the cohesive force of sludge are synergistic with each other, and this synergy reaches the best when the slag content is $30 \%$, effectively compensating for the deterioration of the compressive strength due to the reduction of cement content.

The relationship between the fractal dimension and the compressive strength of baking-free bricks at different sludge content is shown in Fig. 11b. When the sludge content is within $10 \%-20 \%$, both the fractal dimension and the compressive strength decrease; when the sludge content is within $20 \%-50 \%$, the fractal dimension and the compressive strength show a negative correlation. This is because: (1) The fractal dimension is proposed to characterize the degree of irregularity of an object. When the sludge content is within $10 \%$, pores on the baking-free bricks are regular in shape and evenly distributed. In such case, the fractal dimension exhibits less characterization effect, so it decreases first and then 
increases; (2) The increase in fine aggregates enlarges the specific surface area of aggregate particles in the cement mortar. As a result, the aggregates are difficult to be completely wrapped by the cementing material, and thus the cementation at the interface between the gel and aggregates worsens, as shown in Fig. 14a. In addition, irregular pores concentration is more likely to form a weak surface, as shown in Fig. 14b. During the compressive strength test, the micro-cracks around the deteriorated pore structure continuously accumulate and expand rapidly to the mortar body, resulting in fast damage to baking-free bricks [37,38].

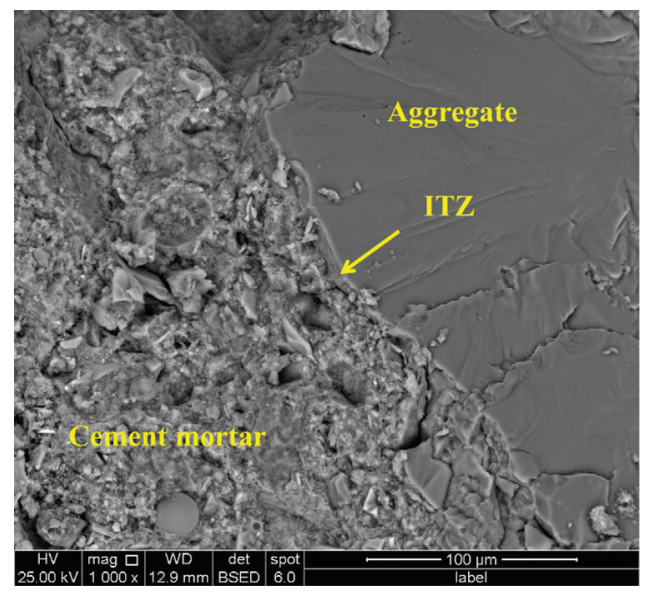

Figure 13: SEM images of SS3 groups

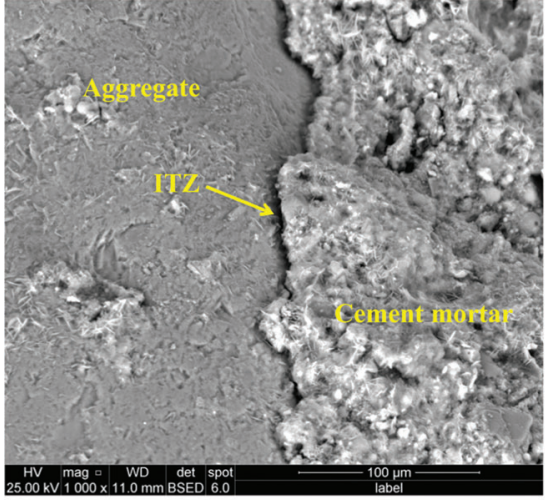

(a)

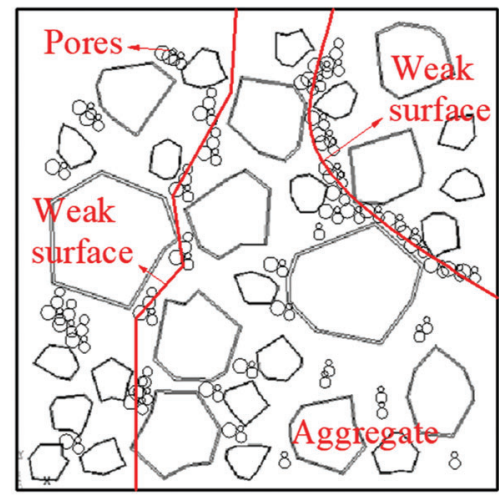

(b)

Figure 14: (a) The SEM images of SS7 groups and (b) The weak surface diagram

The test results show that quantitatively converting the plane pore structure of baking-free brick slices into fractal dimension through imaging technology, PCAS software and Matlab toolbox can accurately describe the influence of different slag and sludge mixing amounts on the pore structure of baking-free bricks. Through the correlation analysis, the effect of the pore structure on the macroscopic properties of baking-free bricks can be further clarified.

\section{Conclusions}

To reduce manufacturing costs, this study uses slag and sludge to prepare high-strength baking-free concrete bricks, and proves the feasibility of this method through experimental investigation, providing a new method for recycling of solid wastes such as slag and sludge. The conclusions are drawn as follows: 
(1) The fractal dimension of the plane pore structure of baking-free bricks calculated by the optical method and computer technology can accurately reflect the variation of the pore structure of baking-free bricks. The plane pore structure of baking-free bricks shows good fractal characteristics. With the increase of the slag content, the fractal dimension becomes smaller and the pore structure develops well; with the increase of the sludge content, the fractal dimension becomes larger and the pore structure becomes worse.

(2) The fractal dimension of the plane pore structure shows a good correlation with the compressive strength, porosity and water absorption rate of baking-free bricks. As the fractal dimension of the plane pore structure increases, the compressive strength of baking-free bricks falls, and the porosity and water absorption rise. Under certain conditions, the macro-mechanical properties of baking-free bricks can be predicted reasonably through the study of their pore structure.

(3) Mixing of slag produces a chemical effect, while mixing of sludge produces a physical effect. The replacement rate of slag can be increased by creating suitable hydration reaction conditions, and the replacement rate of sludge can be increased by improving the accumulation of aggregates. The optimum content of baking-free slag-sludge bricks is slag $30 \%$ and sludge $10 \%$. After 7 days of curing, baking-free bricks boast higher performance, and fully meet the performance requirements of solid concrete bricks (MU40), which can improve the turnover rate of baking-free bricks, reduce time costs, and enhance enterprise revenue.

Acknowledgement: Thank the Key Laboratory of key water conservancy projects of Henan Province for providing test equipment and the help of all partners.

Funding Statement: Science and Technology Project of Henan Water Resources Department support program. No. GG202040. Fund of Innovative Education Program for Graduate Students at North China University of Water Resources and Electric Power, China. No. YK2020-04.

Conflicts of Interest: The authors declare that they have no conflicts of interest to report regarding the present study.

\section{References}

1. Hosam, M. S., Aida, A. S., Abeer, A. F., Abeer, M. (2020). El-Sayed. Sustainable composite of improved lightweight concrete from cement kiln dust with grated poly(styrene). Journal of Cleaner Production, 277, 123491.

2. Nastassia, T. S., Tebogo, M. (2020). Geosynthesis of building and construction materials through alkaline activation of granulated blast furnace slag. Construction and Building Materials, 264, 120712.

3. Ming, Y., Chen, P., Wang, Y. H., Li, L., Chen, X. D. et al. (2020). Experimental research of concrete with steel slag powder and Zeolite powder. Journal of Renewable Materials, 8(12), 1647-1655.

4. Na, H., Lü, G. C., Zhang, D., Wang, L. J., Liao, L. B. (2020). Research progress of typical environmental pollution in polymetallic mining area and its filling and its filling and gel immobilization. Gold Science and Technology, 28(05), 646-657.

5. Lieberman, R. N., Knop, Y., Palmerola, N. M., Munoz, C., Cohen, H. et al. (2019). Production of environmentally friendly sand-like products from granitoid waste sludge and coal fly ash for civil engineering. Journal of Cleaner Production, 238, 117880. DOI 10.1016/j.jclepro.2019.117880.

6. Yaghoubi, M., Arulrajah, A., Disfani, M. M., Horpibulsuk, S., Bo, M. W. et al. (2018). Effects of industrial byproduct based geopolymers on the strength development of a soft soil. Soils and Foundations, 58(3), 716-728. DOI 10.1016/j.sandf.2018.03.005.

7. Nur, A. J., Liew, Y. M., Heah, C. Y., Mohd, M. A. B. A., Kamarudin, H. (2020). Correlation between pore structure, compressive strength and thermal conductivity of porous metakaolin geopolymer. Construction and Building Materials, 247, 118641. 
8. Panesar, D. K., Zhang, R. (2020). Performance comparison of cement replacing materials in concrete: Limestone fillers and supplementary cementing materials-A review. Construction and Building Materials, 251, 118866.

9. Oren, O. H., Gholampour, A., Gencel, O., Ozbakkaloglu, T. (2020). Physical and mechanical properties of foam concretes containing granulated blast furnace slag as fine aggregate. Construction and Building Materials, 238, 117774. DOI 10.1016/j.conbuildmat.2019.117774.

10. Hsieh, Y. C., Cheng, T. W., Wu, C. H. (2020). Feasibility study on fabrication of geopolymer bricks by wasted grinding wheel at room temperature. Journal of renewable materials, 8(12), 1657-1670.

11. Vashistha, P., Kumar, V., Singh, S. K., Dutt, D., Tomar, G. et al. (2019). Valorization of paper mill lime sludge via application in building construction materials: A review. Construction and Building Materials, 211, 371-382. DOI 10.1016/j.conbuildmat.2019.03.085.

12. Sharma, S., Dhaliwal, S. S. (2019). Effect of sewage sludge and rice straw compost on yield, micronutrient availability and soil quality under Rice-Wheat system. Communications in Soil Science and Plant Analysis, 50(16), 1943-1954. DOI 10.1080/00103624.2019.1648489.

13. Xu, Y. T., Yang, B., Liu, X. M., Gao, S., Li, D. S. et al. (2019). Investigation of the medium calcium based nonburnt brick made by red mud and fly ash: Durability and hydration characteristics. International Journal of Minerals, Metallurgy, and Materials, 26(8), 983-991. DOI 10.1007/s12613-019-1814-9.

14. Peng, Y. Z., Peng, X., Yang, M., Shi, H. L., Wang, W. C. et al. (2020). The performances of the baking-free bricks of non-sintered wrap-shell lightweight aggregates from dredged sediments. Construction and Building Materials, 238, 117587. DOI 10.1016/j.conbuildmat.2019.117587.

15. Rahman, Z., Saleh, N., Idris, W., Lihan, T. (2019). Thermal effect on mechanical characteristics of drinking water sludge brick incorporated with Rice Husk Ash. Sains Malaysiana, 48(11), 2541-2549. DOI 10.17576/jsm-2019-4811-24.

16. Carlos, B. D., Gonzalo, M. B., Osman, G., Lina, A. B., Witold, B. (2011). Processed wastewater sludge for improvement of mechanical properties of concretes. Journal of Hazardous Materials, 192(1), 108-115.

17. Zhou, W. T., Yang, F. M., Zhu, R. J., Dai, G., Wang, W. J. et al. (2020). Mechanism analysis of pore structure and crystalline phase of thermal insulation bricks with high municipal sewage sludge content. Construction and Building Materials, 263, 120021.

18. Liu, H. W., Liu, C., Bai, G. L., Zhu, C. (2020). Study on the effect of chloride ion ingress on the pore structure of the attached mortar of recycled concrete coarse aggregate. Construction and Building Materials, 263, 120123.

19. Seneviratne, C., Gunasekara, C., Law, D. W., Setunge, S., Robert, D. (2020). Creep, shrinkage and permeation characteristics of geopolymer aggregate concrete: long-term performance. Archives of Civil and Mechanical Engineering, 20(140), 396.

20. Ren, Y. H., Ren, Q., Huo, Z. Z., Wu, X. L., Zheng, J. L. et al. (2020). Preparation of glass shell fly ash-clay based lightweight aggregate with low water absorption by using sodium carbonate solution as binder. Materials Chemistry and Physics, 256, 123606.

21. Holthausen, R. S., Raupach, M. (2019). Influence of fresh concrete pressure on cover porosity investigated by single-sided proton nuclear magnetic resonance. Magazine of Concrete Research, 73(1), 45-54.

22. Ilker, T., Recep, B., Ismail, O. Y., Osman, G., Huseyin, Y. A. (2015). Monitoring macro voids in mortars by computerized tomography method. Measurement, 63, 299-308. DOI 10.1016/j.measurement.2014.11.034.

23. Lü, Q., Qiu, Q. L., Zheng, J., Wang, J. Y., Zeng, Q. (2019). Fractal dimension of concrete incorporating silica fume and its correlations to pore structure, strength and permeability. Construction and Building Materials, 228, 116986.

24. Tang, S. W., He, Z., Cai, X. H., Cai, R. J., Zhou, W. et al. (2017). Volume and surface fractal dimensions of pore structure by NAD and LT-DSC in calcium sulfoaluminate cement pastes. Construction and Building Materials, 143, 395-418.

25. Standardization Administration of the People's Republic of China (2013). Test methods for the concrete block and brick: GB/T 4111-2013. Beijing: China Standards Press.

26. Liu, C., Shi, B., Zhou, J., Tang, C. S. (2011). Quantification and characterization of microporosity by image processing, geometric measurement and statistical methods: Application on SEM images of clay materials. Applied Clay Science, 54, 97-106. 
JRM, 2021, vol.9, no.10

27. Guo, L. P., Zhu, Q., Ling, S. (2019). Study on basic properties and pore characteristics of recycled aggregate pervious concrete. Water Power, 45, 117-122.

28. Baker, A., Schmidt, W. M. (1970). Diophantine approximation and hausdorff dimension. Proceedings of the London Mathematical Society, 3(1), 1-11. DOI 10.1112/plms/s3-21.1.1.

29. Yu, L. H., Ou, H., Duan, Q. P. (2007). Research on pore volume fractal dimension and its relation to pore structure and strength in cement paste with perlite admixture. Journal of Materials Science and Engineering, 2, 201-204+224.

30. Xing, F. Y., Liu, Y., Yang, W. J., Yu, L., Li, X. L. (2015). Sand fineness and level matching the properties of fresh concrete impact study. Concrete, 1, 118-121+130.

31. Yang, R., Yu, R., Shui, Z. H., Guo, C., Wu, S. et al. (2019). The physical and chemical impact of manufactured sand as a partial replacement material in Ultra-High Performance Concrete (UHPC). Cement and Concrete Composites, 99, 203-213. DOI 10.1016/j.cemconcomp.2019.03.020.

32. Wei, J. X., Yu, Q. J., Zeng, X. X., Bai, R. Y. (2007). Fractal dimension of pore structure of concrete. Journal of South China University of Technology (Natural Science Edition), 35(2), 121-124.

33. Fang, G., Zhang, M. (2020). The evolution of interfacial transition zone in alkali-activated fly ash-slag concrete. Cement and Concrete Research, 129, 105963. DOI 10.1016/j.cemconres.2019.105963.

34. Zajac, M., Skocek, J., Adu-Amankwah, S., Black, L., Ben-Haha, M. (2018). Impact of microstructure on the performance of composite cements: Why higher total porosity can result in higher strength. Cement and Concrete Composites, 90, 178-192. DOI 10.1016/j.cemconcomp.2018.03.023.

35. HoangAnh, N., Chang, T. P., Thymotie, A. (2020). Enhancement of early engineering characteristics of modified slag cement paste with alkali silicate and sulfate. Construction and Building Materials, 230, 117013.

36. Lu, Q. M., Zhen, W., Zhang, R. L., Han, H. Q. (2018). Excitation function of chemical admixture on fly Ash-SlagCement cementitious system. Bulletin of the Chinese Ceramic Society, 37, 2516-2521.

37. Chen, H. S., Sun, W., Piet, S. (2004). Interfacial transition zone between aggregate and paste in cementitious composites (ii): Mechanism of formation and degradation of interfacial transition zone microstructure, and its influence factors. Journal of the Chinese Ceramic Society, 32(1), 70-79.

38. Wu, K., Shi, H. S., Xu, L. L., Gao, Y., Guang, Y. (2017). Effect of mineral admixture on mechanical properties of concrete by adjusting interfacial transition zone microstructure. Journal of the Chinese Ceramic Society, 45, 623-630. 